\title{
Fortalecendo laços: cooperação intermunicipal para redução de risco de desastres
}

\author{
Strengthening ties: inter-municipal cooperation for disaster \\ risk reduction
}

\author{
Silvia Midori Saito [a, b] [D, Fernando Rocha Nogueira [b, c] [D], \\ Luciana de Resende Londe [b] [D, Victor Marchezini [b, d] [D, \\ Kátia Canil [c] [D, Fabiana de Carvalho Rosa [a] [D
}

[a] Universidade Federal de Santa Catarina (UFSC), Programa de Pós-Graduação em Desastres Naturais (PPGDN),

Florianópolis, SC, Brasil

[b] Centro Nacional de Monitoramento e Alertas de Desastres Naturais (Cemaden), São José dos Campos, SP, Brasil

[c] Universidade Federal do ABC (UFABC), Programa de Pós-Graduação em Planejamento e Gestão do Território

(PPGPGT), Santo André, SP, Brasil

[d] Instituto Nacional de Pesquisas Espaciais (INPE), Programa de Doutorado em Ciência do Sistema Terrestre

(PGCST), São José dos Campos, SP, Brasil

Como citar: Saito, S. M., Nogueira, F. R., Londe, L. R., Marchezini, V., Canil, K., \& Rosa, F. C. (2021). Fortalecendo laços: cooperação intermunicipal para redução de risco de desastres. urbe. Revista Brasileira de Gestão Urbana, v.13, e20200403. https://doi.org/10.1590/2175-3369.013.e20200403

\section{Resumo}

A Política Nacional de Proteção e Defesa Civil, instituída pela Lei no 12.608/2012, atribui aos municípios diversas competências em prevenção, mitigação, preparação, resposta e recuperação voltadas à proteção e defesa civil. A realidade dos municípios brasileiros, em especial aqueles de pequeno porte, tem sido a convivência com a escassez de recursos financeiros e humanos para o cumprimento de tais responsabilidades. Este artigo investiga o potencial dos consórcios públicos intermunicipais para a redução das vulnerabilidades, em especial institucional, técnica e política, no contexto de risco de desastres. Por meio de um estudo reflexivo, diversas experiências de consórcios públicos no Brasil foram investigadas, considerando as potencialidades e os desafios enfrentados em sua constituição e manutenção. A capacidade política, financeira e operacional dos consórcios pode viabilizar as atribuições de caráter mais especializado, a exemplo dos mapeamentos de áreas de risco de desastres e dos planos de contingência. Por outro lado, o consórcio por si só não é capaz de resolver todas as dificuldades enfrentadas pelos municípios, sendo necessário ultrapassar entraves políticopartidários e desinteresse da gestão local. Vencidos estes desafios, a cooperação mostra-se com grande potencial para fortalecer as capacidades municipais voltadas para a redução do risco de desastres.

\footnotetext{
SMS é geógrafa, doutora em Geografia, e-mail: silvia.saito@cemaden.gov.br

FRN é geólogo, doutor em Geociências e Meio Ambiente, e-mail: fernando.nogueira@ufabc.edu.br

LRL é bióloga, doutora em Sensoriamento Remoto, e-mail: luciana.londe@cemaden.gov.br

VM é sociólogo, doutor em Sociologia, e-mail: victor.marchezini@cemaden.gov.br

KC foi geógrafa, doutora em Geografia

FCR é bióloga, mestre em Engenharia Ambiental, e-mail: fa_rosa@hotmail.com
} 
Palavras-chave: Defesa civil. Gestão de risco de desastres. Consórcio público.

\section{Abstract}

The National Policy of Protection and Civil Defense (Law 12.608/2012) assigns to municipalities many competences in prevention, mitigation, preparation, response and recovery aimed at civil protection and defense. The reality of Brazilian municipalities, especially small size ones, has been living with the lack of financial and human resources to accomplish these responsibilities. This paper investigates the potential of public intermunicipal consortia to reduce vulnerabilities, especially institutional, technical and political, in the context of disaster risk. Several experiences of public consortia in Brazil were investigated through a reflexive study, considering the potential and the challenges for their constitution and maintenance. The political, financial and operational capacity of consortia could support more specialized activities, such as mapping disaster risk areas and contingency plans. In opposition, the consortium is not able to solve all the difficulties faced by the municipalities, and it is necessary to overcome political-party barriers and indifference of local management. After overcoming these challenges, cooperation shows considerable potential to strengthen municipal capacities for reducing disaster risks.

Keywords: Civil defense. Disaster risk management. Public consortium.

\section{Introdução}

Poucas cidades no mundo contam com um setor voltado para lidar com situações de risco de desastre em áreas urbanas, que trate o assunto de forma holística, estabelecendo uma relação orgânica entre as instituições destinadas para o planejamento setorial, social e territorial (Lavell, 2000). Se, por um lado, as ameaças e vulnerabilidades transcendem os limites municipais, por outro lado, os desastres também exigem a pronta resposta dos governos locais, muitas vezes de forma cooperativa, como será apresentado neste artigo.

O risco de desastres está relacionado ao potencial de perdas de vidas, danos ou bens afetados em um sistema, sociedade ou comunidade, que pode ser determinado em função das ameaças, exposição, vulnerabilidade e capacidade (UNDRR, 2017). Reduzir o risco de desastres requer medidas estruturais, a exemplo de obras de macrodrenagem e de saneamento básico, bem como não estruturais, a exemplo de planejamento urbano e de planos de contingência (Andjelkovic, 2001; Gruntfest, 2000), que podem ser conduzidas por meio de articulação intermunicipal. A ação conjunta entre os municípios pode maximizar os recursos humanos, financeiros e de infraestrutura ao compartilhá-los entre os entes (Ferreira \& Jucá, 2017; Ventura \& Suquisaqui, 2020; Cigainski Lisbinski et al., 2020).

No Brasil, a cooperação ocorre de diferentes maneiras, a exemplo dos comitês de bacias hidrográficas, associações de municípios ou consórcios públicos (CP). Estudos têm demonstrado o alcance de melhorias entre municípios que participam de consórcios, como melhor desempenho em relação aos gastos ambientais, a melhoria do Índice Firjan de Desenvolvimento Municipal e favorecimento da gestão pública (Ribeiro \& Dotto, 2015; Pereira \& Silva Moreira, 2016; Broietti et al., 2020).

Nogueira et al. (2014, p. 181) consideram que uma vez que o federalismo brasileiro está "fortemente ancorado na descentralização de políticas públicas para entes locais autônomos, há uma dificuldade adicional de articulação não apenas intermunicipal, mas também intersetorial". Isso se reflete na fragilidade de se efetuar uma gestão pública integrada considerando os setores do planejamento, habitação, obras, saúde, assistência social, meio ambiente e defesa civil.

$\mathrm{Na}$ temática de riscos e desastres, verificam-se algumas cooperações intermunicipais no Brasil. Na região do Grande $\mathrm{ABC}$ paulista, o Consórcio Intermunicipal Grande $\mathrm{ABC}$ tem apoiado obras de contenção de encostas, capacitação de técnicos, organização de eventos e incremento de sistemas de alerta nos sete municípios consorciados (Consórcio Intermunicipal Grande ABC, 2020). No Rio Grande do Sul, a Oficina Regional Permanente de Proteção e Defesa Civil é realizada de forma periódica entre os oito municípios do 
Vale do Paranhana, Região das Hortênsias e Alto Sinos (Ferentz \& Garcias, 2020). Na Região Serrana do Rio de Janeiro, os municípios de Sumidouro, Três Rios, Paraíba do Sul, Areal e São José do Vale do Rio Preto fizeram um convênio de apoio mútuo, depois da catástrofe de 2011 (Dutra, 2018).

É muito provável que tais iniciativas colaborarem para a redução de algumas vulnerabilidades no contexto de riscos de desastres, em especial as vulnerabilidades política, institucional e técnica. Para Wilches-Chaux (1993) a vulnerabilidade política está relacionada com o alto grau de centralização na tomada de decisão e na organização governamental, somada à fragilidade da autonomia nos níveis locais e regionais, que podem afetar a melhor adequação das decisões aos problemas. Para o autor, a vulnerabilidade institucional reflete a obsolescência e rigidez das instituições, principalmente, as jurídicas, em que a burocracia e predomínio da decisão política e de critérios pessoais, impedem respostas adequadas e ágeis frente à realidade existente; já a vulnerabilidade técnica está relacionada à falta de conhecimento para que o desenvolvimento de atividades que não crie condições de risco.

Ainda que existam iniciativas de cooperação intermunicipal para reduzir as vulnerabilidades, elas ainda são pontuais face à dimensão do desafio em reduzir os riscos de desastres no país. A Política Nacional de Proteção e Defesa Civil, instituída pela Lei no 12.608/2012 (Brasil, 2012), preconiza diversas competências aos municípios, estados e União, em ações de prevenção, mitigação, preparação, resposta e recuperação voltadas à proteção e defesa civil. Muitas delas dependem de conhecimento técnico em diferentes níveis de governo, demandam recursos humanos e/ou materiais, além de planejamento integrado às demais áreas da gestão municipal.

Além da Política Nacional de Proteção e Defesa Civil, mencionada no parágrafo anterior, vale ressaltar que o Plano Plurianual (PPA) 2020-2023 conta com um programa específico para Gestão de Riscos e Desastres (Brasil, 2019). O PPA consiste de políticas públicas ajustadas a cada 4 anos, através de Programas que podem ser classificados como "Programas Finalísticos" ou "Programas de Gestão". No PPA mencionado, o Programa 2218 - Gestão de Riscos e Desastres - tem como único objetivo geral: "Investir na compreensão e redução do risco, ampliar a preparação e reduzir os efeitos dos desastres" (Brasil, 2019). Da forma genérica como está proposto esse objetivo geral, não estão claras as ações federais para o enfrentamento de riscos, tampouco os meios de implementação e orçamentários que os municípios terão para subsidiar suas ações frente às realidades locais com diferentes ameaças e vulnerabilidades.

Perante o exposto, o presente artigo apresenta uma reflexão sobre o potencial dos consórcios públicos intermunicipais para a redução das vulnerabilidades, em especial institucional, técnica e política, no contexto de riscos e desastres. Buscou-se em experiências de consórcios públicos intermunicipais já formalizados, os benefícios alcançados pela prática consorciada, que podem apoiar os municípios no cumprimento de suas competências.

\section{Competências municipais no contexto de riscos e desastres}

Entende-se que a prática da política pública em gestão de riscos de desastres (GRD) dá-se no âmbito local; no entanto, há uma disparidade em relação à vulnerabilidade institucional, política e técnica nos diversos contextos municipais e regionais no Brasil. Mesmo em uma mesma região, essa desigualdade pode ser muito expressiva, a exemplo na Região do Grande $\mathrm{ABC}$, considerando os municípios de São Bernardo do Campo e Rio Grande da Serra, com relação à área, população, Produto Interno Bruto (PIB), Índice de Desenvolvimento Humano (IDH), além dos aspectos técnicos-administrativos da gestão municipal. E é nesse sentido que a existência de um consórcio público (CP) pode fortalecer a cooperação entre municípios e garantir maior representatividade na busca de demandas regionais (Neves \& Ribeiro, 2006; Angnes et al., 2013; Alvares \& Branco, 2018). No entanto, segundo Nogueira et al. (2014) mesmo que nesse modelo se configure um "federalismo cooperativo", compartilhando competências, a própria autonomia política, administrativa e fiscal pode dificultar essa cooperação. Superar essas vulnerabilidades é um desafio para que as competências previstas na Lei n⿳0 12.608/2012 sejam de fato realizadas em sua plenitude. 
No Artigo 8 da lei supracitada diversas responsabilidades são atribuídas às municipalidades, desde a prevenção até os aspectos operacionais em resposta a desastres. Ainda que a Lei no 12.608/2012 não tenha sido totalmente regulamentada, alguns deveres municipais, a exemplo do disposto nos incisos IV e $\mathrm{V}$ (identificar e mapear as áreas de risco de desastres; e promover a fiscalização das áreas de risco de desastre e vedar novas ocupações nessas áreas), seguem com eficácia plena; logo, a falta de obediência pode levar a medidas judiciais ou administrativas preventivas bem como ações compensatórias por danos (Carvalho, 2020). Importante destacar que o Artigo 9 atribui competências comuns à União, Estados e Municípios, o que já sugere a articulação interfederativa.

De acordo com IBGE (2017), entre os anos de 2013 e 2017, constatou-se um aumento no percentual de municípios que declararam contar com instrumentos de planejamento e gerenciamento de risco, dos quais se destacam: i) lei de uso e ocupação do solo voltada à prevenção de enchentes (aumento de 8,3\%) e ii) Plano Diretor que contemple a prevenção de enchentes (aumento de 6,3\%). Em municípios com população superior a 500.000 habitantes, 73,8\% declararam contar com o Plano Municipal de Redução de Risco (PMRR). Contudo, esse percentual reduz drasticamente, sobretudo em municípios de pequeno porte (Saito et al., 2020). 0 PMRR é um documento composto de identificação das áreas de risco e respectivas medidas estruturais e não estruturais, além dos custos destas intervenções (Carvalho \& Galvão, 2006). Trata-se de um instrumento elaborado por corpo técnico composto de profissionais em geociências ou engenharia civil e ambiental, essencial para subsídio à tomada de decisão técnica e política no nível local.

A carta geotécnica de aptidão à urbanização também se constitui como um instrumento que apoia o planejamento territorial, pois, segundo Nogueira \& Canil (2017), trata da síntese do conhecimento sobre o meio físico e seus processos atuantes em uma determinada área, de modo a subsidiar o estabelecimento de medidas para a adequada ocupação do solo. A Lei no 12.608/2012 (Brasil, 2012) recomenda a elaboração de cartas geotécnicas aos municípios brasileiros com "áreas suscetíveis à ocorrência de deslizamentos de grande impacto, inundações bruscas ou processos geológicos ou hidrológicos correlatos". Entretanto, dados do IBGE (2017) mostram que apenas 289 municípios declararam ter desse tipo de carta. Considerando que nem todos os 5570 municípios apresentam suscetibilidade a deslizamentos ou inundações, uma melhor aproximação de quanto ainda se está aquém do ideal, seria considerar a existência da lista de 821 municípios prioritários para ações do Plano Nacional de Gestão de Riscos e Respostas a Desastres (Bertone \& Marinho, 2013). Assim, apenas 35\% dos municípios dispõem dessas cartas.

Tanto o PMRR quanto as cartas geotécnicas exigem mão de obra especializada e insumos cartográficos de boa qualidade, ambos nem sempre disponíveis às inúmeras prefeituras brasileiras. 0 alto custo para a contratação de consultorias torna-se praticamente inviável para muitas delas também.

Os simulados constituem outro instrumento previsto na PNPDEC de competência municipal. Em pesquisa com 81 municípios paulistas, foi constatado que $70 \%$ não se consideravam aptos a realizar simulados e mesmo dentre aqueles que responderam de forma positiva, parte estava confundindo com os simulados realizados pelos Corpo de Bombeiros ou Serviço de Atendimento Móvel de Urgência (SAMU) (Monteiro \& Brito Junior, 2017). Ainda que seja uma amostra pequena, esses dados sugerem que existem dificuldades em realizar atividades que exigem articulação com outros setores, ou mais especializada.

Face ao exposto, nota-se que os municípios necessitam de apoio estadual e federal para colocar em prática os instrumentos de ordenamento e de planejamento urbano, bem como o fortalecimento institucional para fiscalizar e gerir as áreas de risco (Coutinho et al., 2015). Porém, de acordo com o PPA 2020-2023, não há programas específicos com recursos destinados a esses objetivos. Além disso, há urgência na maior interação de instituições e atores locais para promover as ações e as diretrizes da PNPDEC. Essa integração deve ocorrer no âmbito local, como forma de atenuar a fragilidade do apoio das esferas estadual e federal, no nível intermunicipal. Nessa perspectiva, a constituição de consórcios públicos pode fortalecer as competências municipais frente às diversas responsabilidades que lhe são atribuídas na GRD. 


\section{Cooperação intermunicipal por meio de consórcios públicos}

Os CPs e os convênios de cooperação entre os entes federados foram previstos na Emenda Constitucional de 1998 (Brasil, 1998) à Constituição Federal de 1988 (Brasil, 1988). Por meio de lei, ficou estabelecido que a União, Estados, Distrito Federal e Municípios estariam autorizados a realizar a gestão associada de serviços públicos, bem como a transferência total ou parcial de encargos, pessoal e bens essenciais à continuidade dos serviços (Ferracini, 2013a). A estabilidade jurídica, por sua vez, só foi alcançada a partir da Lei no 11.107/2005 (Brasil, 2005), conhecida como Lei dos Consórcios, e promulgação do Decreto no 6.017/2007 (Brasil, 2007), que reconheceram de fato a prática do consorciamento intermunicipal.

O município presta diversos serviços públicos à população, implementa políticas complexas (e.g. educação, segurança, planejamento urbano) e emprega recursos financeiros advindos de sua arrecadação. No Brasil são muitas as disparidades entre os entes federados, que produzem e se caracterizam por inúmeras assimetrias, além das mais variadas e diferentes formas de desequilíbrios regionais e intrarregionais (Batista, 2011). A precariedade técnica, administrativa e financeira tão comum a diversos municípios brasileiros, levou-os a uma maior articulação entre União, estados e municípios (Rocha, 2016).

Os CPs constituem um meio de associação ou união entre municípios, baseada no compartilhamento de interesses e propósitos, com vistas ao provimento de serviços públicos, realização de obras públicas e desenvolvimento sustentável (Cruz, 2006). Segundo o levantamento do CNM (2020), 4081 municípios brasileiros participam de pelo menos um CP. Os consórcios podem atuar em uma ou mais áreas, e segundo o levantamento, foram identificados 275 finalitários, 213 multifinalitários, além de três sem informação, totalizando 491. Dentre aqueles que atuam em apenas uma área, a maior parte é voltada para saúde (181), infraestrutura (20), meio ambiente (12), resíduos sólidos (12) e turismo (7).

Partindo da consulta ao site do Observatório Municipalista de Consórcios Públicos (2020), realizada de 15 a 19 de setembro de 2020, verificou-se que 39 consórcios têm previsão estatutária para atuarem em defesa civil. A região Sudeste concentra a maior parte dos consórcios (10 em São Paulo e 6 em Minas Gerais), seguida da Sul (6 no Rio Grande do Sul; 3 em Santa Catarina e 2 no Paraná), Nordeste (6 na Bahia; 1 em Pernambuco e 1 no Maranhão); Centro Oeste ( 2 em Mato Grosso e 2 no Mato Grosso do Sul) e Norte (1 em Tocantins). Dentre os 39, apenas 38 estavam disponíveis na plataforma, faltando informações de um CP de Mato Grosso do Sul. Dentre aqueles disponíveis, 9 não dispunham de informações sobre o site e 22 não continham notícia ou informação sobre defesa civil. Assim, em apenas 7 sites havia pelo menos menção à defesa civil, mas que basicamente se restringiu a notícias sobre resposta a desastres ou campanhas.

Em São Paulo, foi identificado um consórcio com área temática única em defesa civil: Consórcio Intermunicipal de Bombeiros do Médio Tietê (CIBMT). De acordo com seu estatuto, o CP para "implantação, execução e manutenção de serviço de bombeiro" nos municípios de Tietê, Cerquilho, Jumirim, e Laranjal Paulista, tem por finalidade, a prevenção e extinção de incêndios, busca e salvamento, aprovação de projetos de proteção contra incêndio, fiscalização das normas de prevenção, socorros diversos, entre outras. Notase, que a atuação está voltada a atuar no corpo de bombeiros, não envolvendo outras competências.

Desta forma, não há informação disponível sobre a existência de CPs que atuem considerando o escopo de defesa civil preconizado pela PNPDEC, existindo, assim, espaço para refletir sobre as potencialidades desse instrumento como meio de reduzir vulnerabilidades e colaborar na redução de risco de desastres, em nível local e regional.

\section{Percurso metodológico}

A presente reflexão foi desenvolvida a partir de levantamento bibliográfico sobre consórcios públicos no Brasil. Em uma primeira etapa utilizando os buscadores Google Scholar, Redalyc e portal Periódicos Capes foram encontradas 83 publicações de diferentes naturezas, como trabalhos em anais de eventos, capítulos de livro, relatórios técnicos, monografias, dissertações e teses. Face a tal diversidade, dois critérios 
foram definidos para a seleção dos estudos. 0 primeiro consistiu em considerar exclusivamente artigos em periódicos, tendo em vista a avaliação conduzida por pares, comum a todos. Outro critério foi o recorte temporal, o que levou a seleção de artigos publicados a partir de 2005 (ano da Lei no 11.107, que versa sobre as normas de contratação de consórcios públicos) até setembro de 2020.

As palavras-chave selecionadas para a pesquisa nos buscadores supracitados foram consórcio público, consórcio intermunicipal e cooperação intermunicipal. Como resultado dessa etapa da investigação, foram selecionados 34 artigos que tratam sobre 22 consórcios públicos, além de 14 artigos com foco em múltiplos consórcios, ou com abordagem analítica. A partir da seleção dos artigos, foi realizada a análise das boas práticas e resultados alcançados pelos CPs, assim como dos desafios e lições aprendidas. As definições de vulnerabilidade política, institucional e técnica, propostas por Wilches-Chaux (1993), guiaram a reflexão aqui apresentada.

Algumas limitações dessa análise são reconhecidas: há uma maior proporção de artigos publicados sobre CP em saúde e saneamento básico, o que pode se constituir em um limitante, já que as particularidades dos demais setores não foram contempladas pelo levantamento bibliográfico.

\section{Potencialidades e desafios dos CPs para redução de vulnerabilidades}

Esta seção apresenta a análise sobre o potencial dos CPs na redução de vulnerabilidades, bem como as lições aprendidas. Inicialmente, cumpre compartilhar a consideração feita por Endlich (2018), de que a cooperação intermunicipal "por si só não opera milagres", ou seja, o resultado está diretamente relacionado com os agentes envolvidos, suas intenções e o alcance das mesmas. Ainda que existam constatações concretas sobre os resultados obtidos pelos CPs, há plena ciência de que o sucesso deste instrumento depende de combinação com outros fatores.

Para a superação dos desafios relacionados com a alta centralização de poder (i.e. vulnerabilidade política,), os CPs podem criar condições para estimular a discussão conjunta de tomada de decisão entre seus consorciados. Rocha \& Faria (2004) destacam que as iniciativas de cooperação entre municípios com culturas política e administrativas similares têm maior chance de sucesso. Um exemplo de diálogo foi a formulação do Plano Regional Estratégico pelos entes do Consórcio Intermunicipal do Grande ABC, que definiram as reivindicações prioritárias negociadas com os governos estadual e federal e que foram levadas posteriormente aos presidentes das câmaras municipais, deputados e senadores da região do Grande $\mathrm{ABC}$ (Ferracini, 2013b).

Os CPs podem fortalecer a criação de uma identidade regional (Xavier et al., 2013). Mendonça \& Andrade (2018) sugerem que o CP pode constituir-se como ferramenta para construção de tal identidade através de empoderamento dos municípios, sob enfoque técnico, político e administrativo. A descentralização de políticas públicas proporciona a neutralização de divergências e carências regionais (Falcão \& Araújo, 2011). A identidade também pode ser fortalecida do ponto de vista individual, a exemplo do Consórcio Intermunicipal de Desenvolvimento da Região Caparaó, que fomentou a identidade citadina "Caparaó", estimulando o pertencimento local dos moradores de onze municípios capixabas (Madeira Filho et al., 2020).

A gestão por meio do consorciamento é significativa, dada sua capacidade política, financeira e operacional (Fonsêca Júnior et al., 2015). Segundo a Lei dos Consórcios, a aquisição de bens e serviços é feita por meio do autofinanciamento entre os consorciados, cuja contribuição é proporcional à receita do município; em se tratando da operacionalização das ações do CP, a administradora do consórcio executa as decisões tomadas entre os consorciados. Enquanto uma associação pública, um CP pode realizar licitação para compras conjuntas; conseguir a dispensa de licitação para contratar entes da federação ou entidades de sua administração direta e realizar fiscalização tributária conjunta (Consórcio Intermunicipal Grande ABC, 2020; Ribeiro \& Dotto, 2015).

Nunes Rodrigues (2011) destaca que cooperação intermunicipal leva à valorização das lógicas locais nos processos de definição e tratamento de problemas públicos. De certa maneira, a gestão compartilhada 
de políticas públicas aumenta a visibilidade da região perante os níveis estaduais, federal e internacional (Henrichs \& Meza, 2017). 0 consórcio também pode ser uma resposta dos municípios frente à necessidade de reorientação de políticas federais e estaduais ou ausência delas (Azevedo, 2005).

0 CP também pode levar à redução de vulnerabilidade socioeconômica em regiões mais carentes, ao ajustar esforços entre União, estados e municípios em prol do desenvolvimento econômico (Ribeiro \& Razuk, 2014). O Consórcio Intermunicipal da Fronteira, por exemplo, diante da deficiência comum de pessoal qualificado para captação de recursos junto às fontes, buscou parcerias junto ao SEBRAE (Serviço Brasileiro de Apoio às Micro e Pequenas Empresas), governos estaduais e federal (Andreatta, 2015). Os CPs ainda podem apoiar as ações e políticas de desenvolvimento urbano, socioeconômico local e regional, conforme disposto no Decreto no 6.017/2007 (Brasil, 2007), como observado na área da saúde (Andrade et al., 2020; Falcão \& Araújo, 2011; Kranz \& dos Santos Rosa, 2015, Filippim et al., 2018); infraestrutura rodoviária urbana e rural (Maia et al., 2020) e mobilidade urbana (Ré \& Oliveira, 2018).

A articulação político-administrativa na escala regional também pode ser fomentada pelo CP (Amaral \& Blatt, 2011; Camatta \& Sousa Filho, 2014; Ferreira \& Jucá, 2017; Fonsêca Júnior et al., 2015; Mendonça \& Andrade, 2018; Ré \& Oliveira, 2018; Thesing et al., 2018; Lisbinski et al., 2020; Fernandes et al., 2020), que pode potencializar a ação coletiva municipal e fortalecer os territórios. Decisões tomadas em conjunto pelos consorciados coíbem interesses individuais, impulsionando a prática coletiva. Soma-se, ainda, a possibilidade de integração regional ascendente, ou seja, de diferentes setores, que podem levar ao desenvolvimento de política municipal descentralizada (Ventura \& Suquisaqui, 2020). As experiências estudadas também apontam para maior interação com outras organizações da sociedade civil, proporcionando participação social na busca de soluções integradas. Tais aspectos podem, portanto, contribuir para o enfrentamento de vulnerabilidades institucionais, em especial, relacionadas aos problemas de predomínio da decisão política e de critérios pessoais.

Diante das experiências analisadas em CPs nas mais diversas áreas, um rol de lições aprendidas também pôde ser listado. Um primeiro aspecto trata-se da própria concepção dos CPs, que podem levar ao seu sucesso ou fracasso. A decisão de se criar o CP deve vir pelos próprios consorciados, ou seja, de caráter voluntário (Endlich, 2018). Determinações técnicas tomadas pelo governo estadual nem sempre resultam em práticas cooperativas duradouras. Por exemplo, devido à Lei no 12.305/2010 (Brasil, 2010), que instituiu a Política Nacional de Resíduos Sólidos, Estados estabeleceram seus planos. Em São Paulo, o Plano de Resíduos Sólidos propôs soluções compartilhadas entre microrregiões, mas as recomendações foram insuficientes para estruturar um plano consistente, levando até mesmo à redução de práticas consorciadas (Simão et al., 2018).

Algumas experiências mostraram a relação assimétrica entre os consorciados, especialmente quando constituídos por municípios de diferentes portes (Alvares \& Branco, 2018; Nascimento Neto \& Moreira, 2012). Diferenças também podem existir dada a cultura política municipalista, especialmente mais forte no Sul e Sudeste, se comparado ao Nordeste do Brasil (Britto et al. 2016). Laczynski \& Teixeira (2012), em estudo sobre o Consórcio Intermunicipal de Produção e Abastecimento (CINPRA), formado por 15 municípios do Maranhão, recomendam a construção de acordos organizacionais horizontais de cooperação entre governos locais com base na associação voluntária, para corroborar no fortalecimento dos laços entre consorciados.

A formalização dos direitos, deveres e penalidades entre os consorciados também colabora para a sustentabilidade dos CPs, dada a clareza das regras diante do não cumprimento das obrigações pelos entes participantes (Silveira \& Philippi, 2008). Ventura \& Suquisaqui (2020) sugerem que o protocolo de intenções seja ratificado pelos consorciados após discussão conjunta, evitando assim o descumprimento dos acordos estabelecidos. Os custos e benefícios entre os consorciados também deve ser previsto em dispositivos legais, de modo a garantir estabilização das parcerias e reduzir conflitos entre consorciados (Machado \& Andrade, 2014).

Vencida a etapa de concepção do CP, outro aspecto relevante constatado constitui-se na incorporação de modelos de gestão. Aqueles pré-concebidos e sem aderência à realidade local ou às condições históricas 
dificultam a obtenção de resultados concretos entre os consorciados. Lorenzo \& Fonseca (2008) identificaram que o modelo italiano não foi adequado para o caso do Consórcio Intermunicipal Central Paulista, pois uma articulação intersetorial prévia era essencial, que não existia à época. Galindo et al. (2014) também chamaram a atenção para os CPs fundamentados na racionalidade das organizações do mercado, que não condizem com a realidade da gestão pública.

Para a manutenção dos CPs ao longo do tempo, os artigos analisados destacam diversos desafios a serem sobrepujados, tais como:

- o desinteresse dos prefeitos, a falta de estrutura e a pluralidade política partidária (Silva Filho \& de Barros Corrêa, 2017; Ré \& Oliveira, 2018);

- a falta de liderança pelo consórcio em prática de políticas públicas entre os municípios consorciados, o favorecimento ao município sede do consórcio (Bueno \& Motta, 2011; Lorenzo et al., 2014; Marinho \& Ferreira, 2019);

- o enfrentamento da arraigada cultura do individualismo municipal para criação de sinergias voltadas ao desenvolvimento regional (Lorenzo \& Fonseca, 2008; Oliveira, 2013);

- o peso político como obstáculo para avanço da gestão do programa (Alvares \& Branco, 2018; Carneiro \& Souza, 2016; Lauermann Koch et al., 2016);

- maior participação social e/ou dos atores diretamente envolvidos (Dallabrida \& Zimermann, 2009; Nascimento Neto \& Moreira, 2012; Xavier et al., 2013; Julião \& Olivieri, 2020; Kasahara et al., 2020).

\section{Consórcios públicos em defesa civil: um caminho viável}

Diante do exposto, nota-se que o CP pode contribuir para a redução das vulnerabilidades no contexto de risco e desastres, além de apoiar na implementação da PNPDEC. Considerando que esta política tem como diretriz a abordagem sistêmica em prevenção, mitigação, resposta e recuperação em seu Art. 4, constata-se o potencial de se articular com CPs finalitários e multifinalitários, de outras áreas, que guardam relação com risco e desastres, como meio ambiente, infraestrutura, assistência social, planejamento urbano, entre outras. Esta seção evidencia alguns aspectos de como os CPs possam embasar suas ações no âmbito de proteção e defesa civil.

As capacidades e necessidades municipais em proteção e defesa civil que podem ser abordadas pelos CPs são diversas. Em questionários aplicados a profissionais de defesa civil por Londe et al., (2015), as respostas apontaram para: i) a necessidade de desenvolvimento de atividades informativas e de orientação com a população em geral; ii), de composição dos cargos por concursos em vez de indicação; iii) e estabelecimento de um plano de carreira para garantir a continuidade das ações contando com a experiência dos agentes e com a confiança da população; iv). As respostas também ressaltam a importância de fortalecer relações com a população e com instituições parceiras; v) e de contar com outros recursos e instrumentos, como o Plano Diretor com especificação das áreas de risco, com respaldo em cartas geotécnicas e topográficas; vi) necessidades de equipamentos e material de consumo básicos. Também é preciso ter disponibilidade de viaturas e combustível para deslocamento até os locais a serem monitorados, uniformes, equipamentos de proteção, entre outros. Outra fragilidade apontada corresponde aos níveis de governo e aos entraves burocrático-partidários. A dificuldade mais importante, que permeia a maioria das respostas, é a comunicação em todas as suas esferas, em nível local, estadual e federal, de forma institucional ou direta com a população.

A capacidade política, financeira e operacional dos CPs pode viabilizar as atribuições de caráter técnico (i.e. mapeamento das áreas de risco de desastres, fiscalização, redes de monitoramento de baixo custo, organização de abrigos temporários, planos de contingência e simulados, capacitação de radioamadores, logística de donativos, destinação adequada aos escombros e resíduos em um desastre) seja pela contratação de serviços ou mesmo compartilhando recursos humanos quando disponíveis entre os 
municípios. Outras atribuições também se beneficiam da melhor articulação intermunicipal, especialmente aquelas com caráter regional, como as parcerias com entidades públicas e privadas, cuja atuação muitas vezes não se restringem a um município. Várias dessas ações estão presentes no Marco de Ação de Sendai, que recomenda a abordagem multisetorial, de modo a criar oportunidades de colaboração, incentivando que até mesmo as empresas integrem o risco de desastres em suas práticas de gestão (UNISDR, 2015). Estes aspectos podem promover a análise do território de forma integrada, considerando as ameaças, vulnerabilidades, capacidades e políticas de mitigação de riscos entre os consorciados.

A parceria com as universidades permite o desenvolvimento de diversas práticas em GRD, a exemplo da cartografia de risco e práticas em educação para prevenção de desastres. Ao longo do ano de 2019, a equipe de pesquisadores do Laboratório de Gestão de Riscos (LabGRis) da UFABC ofereceu oito oficinas aos técnicos envolvidos em GRD dos cinco municípios articulados em torno do Consórcio Intermunicipal da Bacia do Juqueri (CIMBAJU) - Caieiras, Cajamar, Francisco Morato, Franco da Rocha e Mairiporã, todos na porção noroeste da Região Metropolitana de São Paulo. Esse projeto de extensão "Caminhos Participativos para Gestão de Riscos e Desastres" teve como objetivo principal "desenvolver pesquisa-ação em prática extensionista, buscando validar, adequar ou construir novas técnicas e procedimentos para a gestão de risco, tendo por foco central a coprodução do conhecimento, junto com técnicos e gestores locais e com a população residente em áreas de risco de cinco municípios da Região da Bacia do Juqueri" (Nogueira et al., 2021, p. 193). As oficinas trataram de temas diversos: no tópico sobre gestão integral de riscos, os participantes debateram as consequências de potenciais empreendimentos imobiliários no cenário de risco regional; na oficina sobre geoprocessamento, os participantes apontaram os principais problemas ambientais de seus municípios, buscando entender suas causalidades dentro de toda a bacia hidrográfica e, especialmente, compreender os impactos locais associados às eventuais aberturas das comportas da Represa Paiva Castro em momentos de cheias, a qual fica a montante da região (Figura 1).
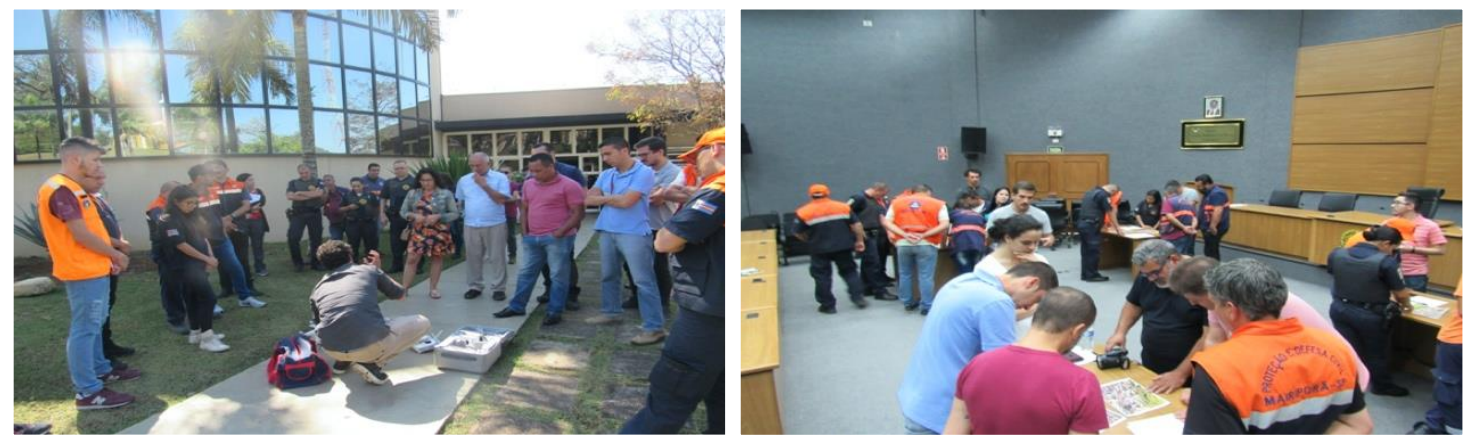

Figura 1 - atividades realizadas durante a oficina sobre uso de Veículos Aéreos Não Tripulados (VANT), com participação de técnicos dos cinco municípios do CIMBAJU. Foto: LabGRis (2019).

O problema de composição dos cargos de defesa civil por indicação poderia ser contornado pelos CP, fazendo a contratação pela pessoa jurídica dos consórcios e evitando as trocas frequentes do corpo de profissionais. Desta forma seria mais fácil também estabelecer e consolidar planos de carreira, bem como promover articulação contínua entre os técnicos.

Relacionando os dados da pesquisa de Londe et al. (2015) com as lições aprendidas pelos consórcios, é possível encontrar caminhos que convergem para redução de vulnerabilidades. Por exemplo, é plausível o investimento dos CPs em mapeamentos de forma integrada, a exemplo das cartas geotécnicas de aptidão à urbanização para municípios de uma mesma bacia hidrográfica, ou região, de forma que todos usem estes dados para um gerenciamento coletivo e compartilhado. Também é esperado que os entraves burocráticopartidários diminuam em ações de consórcio. A comunicação continua sendo um aspecto-chave: é apontada como uma grande dificuldade nas ações isoladas das defesas civis, mas pode também determinar o sucesso ou o fracasso dos consórcios, dependendo da forma como for conduzida.

Conforme exposto anteriormente, ainda que existam 39 CPs em defesa civil no Brasil, não foi possível verificar se a atuação vem sendo realizada alinhada à PNPDEC. Considerando que já foi vencida a etapa de 
constituição formal de tais CPs, o desenvolvimento de ações intermunicipais em prevenção, mitigação, preparação, resposta a desastres pode ser incentivado por meio de intercâmbio de boas práticas e de espaços para diálogo permanente entre os entes consorciados, com ampla participação social.

\section{Conclusões}

Novos e velhos desafios na gestão pública têm mostrado cada vez mais a necessidade de articulação local para a convivência com o risco de desastres. A reflexão aqui apresentada mostrou que o CP pode colaborar para a redução das vulnerabilidades política, institucional e técnica, dado seu potencial em promover fórum de discussão entre consorciados, maior poder de negociação junto a esferas estadual e federal, bem como autonomia financeira. Por outro lado, como exposto nesta análise, existem várias dificuldades que precisam ser vencidas para a constituição e manutenção dos CPs.

Ainda que existam alguns consórcios com previsão estatutária para atuação em defesa civil, não foi possível verificar se a atuação vem sendo realizada à luz da integração entre prevenção, mitigação, preparação, resposta e recuperação de desastres. Não se defende que um CP de defesa civil necessite ter este tópico como finalidade única, até mesmo porque a PNPDEC sugere como diretriz a integração com outras políticas públicas. 0 exemplo da COVID-19 fez saltar a olhos vistos a premência de articulação intersetorial, embasamento técnico e participação social para lidar com os efeitos da pandemia. Os impactos ainda perdurarão ao longo do tempo, levando a crer que seu enfrentamento exigirá ainda mais ação coordenada, com participação intersetorial e nos três níveis de governo. A articulação intermunicipal pode levar a uma prática em proteção e defesa civil em escala regional, na valorização das realidades locais e promoção de federalismo cooperativo.

\section{Dedicatória}

Este artigo é dedicado à memória de Kátia Canil (1969 - 2021), professora e amiga insubstituível, que partiu cedo demais.

\section{Agradecimentos}

Silvia Midori Saito agradece ao Conselho Nacional de Desenvolvimento Científico e Tecnológico (CNPq), Processo 420603/2016-6.

\section{Referências}

Alvares, M. A. A., \& Branco, M. S. (2018). Captação de recursos via transferências voluntárias: um olhar para os municípios do Consórcio Intermunicipal da Região Oeste Metropolitana de São Paulo (Cioeste). Revista do Serviço Público, 69(3), 605630. https://doi.org/10.21874/rsp.v69i3.3540

Amaral, S. M. S. do, \& Blatt, C. R. (2011). Consórcio intermunicipal para a aquisição de medicamentos: impacto no desabastecimento e no custo. Revista de Saúde Pública, 45, 799-801. https://doi.org/10.1590/S003489102011005000016

Andjelkovic, I. (2001). International Hydrological Programme Guidelines on Non-Structural Measures in Urban Flood Management. Recuperado em 30 de janeiro de 2020, de http://unesdoc.unesco.org/images/0012/001240/124004e.pdf

Andrade, L. D. F. de, Santos, N. C. C. de B., Leano, H. A. de M., Sousa, W. B. de, Fernandes, C. S. P., \& Andrade, J. G. de. (2020). Potencialidades e limitações do consórcio intermunicipal de saúde na opinião dos usuários. Educação, Ciência e Saúde, 7(1), 189-202. https://doi.org/10.20438/ecs.v7i1.258

Andreatta, A. (2015). Cooperação transfronteiriça e desenvolvimento regional: o caso do consórcio intermunicipal da fronteira (CIF). Orbis Latina, 5(2), 64-79. Recuperado em 14 de setembro de 2020, de https://revistas.unila.edu.br/orbis/article/view/412/360 


\section{Fortalecendo laços}

Angnes, J. S., Mattos, S. M. M., Klozovski, M. L., \& Sturm, M. I. (2013). Consórcio Intermunicipal da Fronteira (CIF): Descrevendo as principais ações voltadas ao desenvolvimento regional a partir da perspectiva do poder público municipal. Revista de Administração Pública, 47(5), 1165-1188. https://doi.org/10.1590/S0034-76122013000500005

Azevedo, S. de (2005). Poder local, federalismo y gestión metropolitana en Brasil. Ciudad y Territorio Estudios Territoriales, 625-634. Recuperado em 14 de setembro de 2020, de https://recyt.fecyt.es/index.php/CyTET/article/view/85770

Batista, S. (2011). Guia de Consórcios Públicos: Caderno 1 - O papel dos prefeitos e prefeitas na criação e na gestão de consórcios públicos. Recuperado em 12 de setembro de 2020, de https://central3.to.gov.br/arquivo/280365/

Bertone, P., \& Marinho, C. (2013). Plano de Gestão de Riscos e Resposta a Desastres Naturais- - Visão do Planejamento. In: VI Congresso CONSAD de Gestão Pública, (1-24). Brasília: CONSAD.

Brasil (1988). Constituição da República Federativa do Brasil de 1988. Diário Oficial da União.

Brasil (1998. 4 de junho). Emenda constitucional nº 19, de 4 de junho de 1998. Modifica o regime e dispõe sobre princípios e normas da Administração Pública, servidores e agentes políticos, controle de despesas e finanças públicas e custeio de atividades a cargo do Distrito Federal, e dá outras providências. Diário Oficial da União.

Brasil (2005, 6 de abril). Lei no 11.107, de 17 de janeiro de 2007. Dispõe sobre normas gerais de contratação de consórcios públicos e dá outras providências. Diário Oficial da União.

Brasil (2007, 17 de janeiro). Decreto no 6.017, de 17 de janeiro de 2007. Regulamenta a Lei no 11.107, de 6 de abril de 2005, que dispõe sobre normas gerais de contratação de consórcios públicos. Diário Oficial da União.

Brasil (2010, 2 de agosto). Lei no 12.305, de 2 de agosto de 2010. Institui a Política Nacional de Resíduos Sólidos; altera a Lei no 9.605, de 12 de fevereiro de 1998; e dá outras providências. Diário Oficial da União.

Brasil (2012, 10 de abril). Lei no 12.608, de 10 de abril de 2012. Institui a Política Nacional de Proteção e Defesa Civil PNPDEC; dispõe sobre o Sistema Nacional de Proteção e Defesa Civil- - SINPDEC e o Conselho Nacional de Proteção e Defesa Civi- - CONPDEC; autoriza a criação de sistema de informações e monitoramento de desastres; altera as Leis $n^{\circ} \mathbf{S}$ 12.340, de $1^{\text {o }}$ de dezembro de 2010, 10.257, de 10 de julho de 2001, 6.766, de 19 de dezembro de 1979, 8.239, de 4 de outubro de 1991, e 9.394, de 20 de dezembro de 1996; e dá outras providências. Diário Oficial da União.

Brasil (2019, 27 de dezembro) Lei no 13.971, de 27 de dezembro de 2019. Institui o Plano Plurianual da União para o período de 2020 a 2023. Diário Oficial da União.

Britto, A. L. N. P., Maiello, A., Mello, Y., \& Barbosa, P. (2016). Experiências de cooperação interfederativa no Brasil. Reflexões a partir de um estudo comparativo de consórcios intermunicipais de saneamento básico. Revista Política e Planejamento Regional, Rio de Janeiro, 3(2), 159-180.

Broietti, C., Souza, J. A. S. de, Flach, L., Silva, G. C., \& Ferreira, C. D. (2020). The Impact of Public Consortium in Environmental Spending from Municipalities in Southern Brazil. Ambiente \& Sociedade, 23, 1-18. https://doi.org/10.1590/1809-4422asoc20190127vu2020l1ao

Bueno, J. B. D., \& Motta, I. D. da M. (2011). Instrumentos para Efetivação do Direito à Saúde como Direito da Personalidade: Consórcio Público Intermunicipal de Saúde do Setentrião Paranaense-CISAMUSEP e sua Aplicabilidade. Revista Jurídica Cesumar-Mestrado, 11(2), 481-493.

Camatta, A. F. A., \& Sousa Filho, A. F. (2014). Consórcio público como instrumento da gestão associada para a sustentabilidade ambiental sob a ótica dos afetados. Revista Juridica, 1(34), 155-177.

https://doi.org/10.21902/revistajur.2316-753X.v1i34.790

Carneiro, C. M. M., \& Souza, M. K. B. de. (2016). Cooperação intermunicipal na percepção de gestores de saúde. Revista Baiana de Saúde Pública, 40(3). 754-771. https://doi.org/10.22278/2318-2660.2016.v40.n3.a1973

Carvalho, C. S., \& Galvão, T. (2006). Prevenção de Riscos de Deslizamentos em Encostas: Guia para Elaboração de Políticas Municipais. Ministério das Cidades; Cities Alliance. Recuperado em 12 de setembro de 2020, de http://planodiretor.mprs.mp.br/arquivos/prevencaoriscos.pdf

Carvalho, D. W. (2020). A natureza jurídica da Pandemia COVID-19 como um desastre biológico: um ponto de partida necessário para o Direito. Revista Dos Tribunais, 1017. Recuperado em 10 de setembro de 2020, de https://www.prefeitura.sp.gov.br/cidade/secretarias/upload/CEJUR\%20-

\%20PGM/CEJUR\%20Clipping/5\%c2\%aa\%20Edi\%c3\%a7\%c3\%a3o/Artigos/9.pdf. 


\section{Fortalecendo laços}

Cigainski Lisbinski, F., Balestrin Flores, C. E., Da Silva, D. M., Pereira Bisognin, R., \& Gehlen Bohrer, R. E. (2020). A importância dos Consórcios Públicos na gestão dos resíduos sólidos urbanos: uma análise do consórcio intermunicipal Cigres. Revista Gestão \& Sustentabilidade Ambiental, 9(2), 3-36. https://doi.org/10.19177/rgsa.v9e220203-36

Confederação Nacional dos Municípios - CNM. (2020). Consórcios públicos intermunicipais: estrutura, prestação de contas e transparência. Recuperado em 9 de setembro de 2020, de https://www.cnm.org.br/cms/biblioteca/Consorcios-publicosintermunicipais-2ed.pdf

Consórcio Intermunicipal Grande ABC (2020). GT Gestão de Riscos. Recuperado em 14 de setembro de 2020, de http://consorcioabc.sp.gov.br/gt-defesa-civil

Coutinho, M. P., Londe, L. de R., Santos, L. B. L., \& Leal, P. J. V. (2015). Instrumentos de planejamento e preparo dos municípios brasileiros à Política de Proteção e Defesa Civil. Urbe. Revista Brasileira de Gestão Urbana, 7(3), 383-396. https://doi.org/10.1590/2175-3369.007.003.A006

Cruz, C. M. T. (2006). Cooperación Intermunicipal: la discusión de los acuerdos institucionales como instrumento para el Desarrollo Local y la experiencia paulista. Medio Ambiente y Urbanización, 64(1), 57-75.

Dallabrida, V. R., \& Zimermann, V. J. (2009). Descentralização na gestão pública e estruturas subnacionais de gestão do desenvolvimento: 0 papel dos consórcios intermunicipais. Revista Brasileira de Gestão e Desenvolvimento Regional, 5(3), 3-28.

Dutra, A. S. (2018). Gestão de desastres e serviço social: o trabalho de assistentes sociais junto aos órgãos municipais de proteção e defesa civil. Rio de Janeiro: Lumen Juris.

Endlich, A. M. (2018). Cooperações intermunicipais em áreas não-metropolitanas. Redes, 23(3), 95-116. https://doi.org/10.17058/redes.v23i3.12065

Falcão, E. C., \& Araújo, M. L. C. de. (2011). Políticas Públicas de Saúde: um estudo de caso no Centro de Especialidade Odontológica do Consórcio Público de Saúde da Microrregião de Russa- - CE. Conhecer: Debate Entre o Público e o Privado, 2, 579-616.

Ferentz, L. M. da S., \& Garcias, C. M. (2020). A capacidade do Estado frente a gestão de riscos e desastres após a Política Nacional de Proteção e Defesa Civil (Lei 12.608/2012). Revista Brasileira de Políticas Públicas, 10(1). 244-267. https://doi.org/10.5102/rbpp.v10i1.6550

Fernandes, A. S. A., Pinheiro, L. S., Nascimento, A. B. F. M. do, \& Grin, E. J. (2020). An analysis of intermunicipal consortia to provide waste services based on institutional collective action. Revista de Administração Pública, 54(3), 501-523. https://doi.org/10.1590/0034-761220190237x

Ferracini, K. R. (2013a). Articulador Para Executor de Políticas Públicas de Interesse Comum? RBPD. Revista Brasileira de Planejamento e Desenvolvimento, 2(1), 47-58.

Ferracini, K. R. (2013b). Desafios do consórcio intermunicipal do AB- - de articulador para executor de políticas públicas de interesse comum? Revista Brasileira de Planejamento e Desenvolvimento, 2(1), 47-58. https://doi.org/10.3895/rbpd.v2n1.3085

Ferreira, C. F. A., \& Jucá, J. F. T. (2017). Metodologia para avaliação dos consórcios de resíduos sólidos urbanos em Minas Gerais. Engenharia Sanitária e Ambiental. 22 (3), 513-521. https://doi.org/10.1590/S1413-41522017147551

Filippim, E. S., Moreira, E. A., \& Cetolin, S. F. (2018). Consórcios Públicos e Desenvolvimento: o caso do Consórcio Intermunicipal de Saúde do Oeste de Santa Catarina. Redes (St. Cruz Sul, Online), 23(3), 165-187. https://doi.org/10.17058/redes.v23i3.6284

Fonsêca Júnior, B. V., Ramalho, A. M. C., da Silva, S. S. F., Alves, A. C., de Melo, A. S., \& de Sousa Lacerda, C. (2015). 0 Consórcio Público Intermunicipal de Saúde do Curimataú e Seridó Paraibano. Qualitas Revista Eletrônica, 16(2), 116-136.

Galindo, J. M., Cordeiro, J. C., Villani, R. A. G., Barbosa Filho, E. A., \& Rodrigues, C. S. (2014). Gestão interfederativa do SUS: A experiência gerencial do consórcio intermunicipal do Sertão do Araripe de Pernambuco. Revista de Administração Pública. 48(6), 1545-1566. https://doi.org/10.1590/0034-76121478

Gruntfest, E. (2000). Nonstructural mitigation of flood hazards. In: Wohl, E.E. Inland Flood Hazards: Human Riparian and Aquatic Communities. p. 394-410. Cambridge: Cambridge University Press.

https://doi.org/10.1017/cbo9780511529412.016.

Henrichs, J. A., \& Meza, M. L. F. G. de. (2017). Governança multinível para o desenvolvimento regional: um estudo de caso do Consórcio Intermunicipal da Fronteira. Urbe. Revista Brasileira de Gestão Urbana, 9(1), 124-138.

https://doi.org/10.1590/2175-3369.009.0 


\section{Fortalecendo laços}

Instituto Brasileiro de Geografia e Estatística - IBGE. (2017). Perfil dos Municípios Brasileiros 2017. Recuperado em 1 de julho de 2020, de https://www.ibge.gov.br/estatisticas/sociais/saude/10586-pesquisa-de-informacoes-basicasmunicipais.html?edicao $=21632 \& \mathrm{t}=$ destaques

Julião, K. S., \& Olivieri, C. (2020). Cooperação intergovernamental na política de saúde: a experiência dos consórcios públicos verticais no Ceará, Brasil. Cadernos de Saúde Pública, 36(3). 1-12. https://doi.org/10.1590/0102-311x00037519

Kasahara, Y., Sobral, M. do C., \& Melo, M. G. de S. (2020). The local dimension in water resources governance: the experience of inter-municipal consortia and committees on river basins. Revista Brasileira de Ciências Ambientais (Online), 55(3), 282297. https://doi.org/10.5327/Z2176-947820200711

Kranz, L. F., \& dos Santos Rosa, R. (2015). Consórcio intermunicipal do vale do rio caí (CIS/CAÍ): serviços prestados de média e alta complexidade em saúde. Gestão e Sociedade, 9(23), 946-960.

LabGRis (2019). Laboratório de Gestão de Riscos. Acervo fotográfico.

Laczynski, P., \& Teixeira, M. (2012). Os limites de um consórcio intermunicipal em condições assimétricas de poder: o caso do Cinpra no Maranhão. Cadernos Adenauer, 12 (4), 141-160.

Lauermann Koch, L., Barichello, R., \& Jacoski, C. A. (2016). Um estudo sobre as Partes Interessadas do Programa Mercado Público Regional (MPR) no âmbito do Consórcio Intermunicipal de Desenvolvimento Econômico, Social e Meio AmbienteCIDEMA com base no PMIR. Revista Produção e Desenvolvimento. 2(2), 50-63. https://doi.org/10.32358/rpd.2016.v2.144

Lavell, A. (2000). Desastres urbanos: una visión global. Panamá: Facultad Latinoamericana de Ciencias Sociales. 1-11. Recuperado em 10 de setembro de 2020, de https://www.preventionweb.net/files/11007_DUUVGmar120021.pdf

Lisbinski, F. C., Flores, C. E. B., da Silva, D. M., Bisognin, R. P., \& Bohrer, R. E. G. (2020). A Importância dos Consórcios Públicos na Gestão dos Resíduos Sólidos Urbanos: uma análise do Consórcio Intermunicipal Cigres. Revista Gestão \& Sustentabilidade Ambiental, 9(2), 3-36.

Londe, L. D. R., Soriano, E., \& Coutinho, M. P. (2015). Capacidades das instituições municipais de Proteção e Defesa Civil no Brasil: desafios e perspectivas. Revista do Departamento de Geografia, 30 (2015), 77-95.

https://doi.org/10.11606/rdg.v30i0.98715

Lorenzo, H. C. De, \& Fonseca, S. de A. (2008). A promoção do desenvolvimento local apoiada em redes de municípios: a experiência do Consórcio Intermunicipal Central Paulista. Interações (Campo Grande), 17 (3), 366-382.

https://doi.org/10.1590/s1518-70122008000100006

Lorenzo, H. C. de, Fonseca, S. A., \& Ferreira, D. A. de O. (2014). O consórcio do Rio Jacaré: limites e desafios para a cooperação intermunicipal e para o desenvolvimento regional. FACEF Pesquisa: Desenvolvimento e Gestão, 17(3), 366-382. Recuperado em 9 de setembro de 2020, de http://hdl.handle.net/11449/125277

Machado, J. A., \& Andrade, M. L. C. (2014). Cooperação intergovernamental, consórcios públicos e sistemas de distribuição de custos e benefícios. Revista de Administração Pública. 48 (3), 695-720. https://doi.org/10.1590/0034-76121626

Madeira Filho, W., Simon, A. V. S., \& Garcia, C. M. H. (2020). Efeitos colaterais na conservação: o caso do consórcio público da região Caparaó. Brazilian Journal of Business, 2(1), 372-385.

Maia, C. M., Randolph, R., Pimentel, M. L., \& Bigaton, I. C. (2020). Atuação do Consórcio Intermunicipal Catarinense (CIMCATARINA): qual sua contribuição ao desenvolvimento regional? COLÓQUIO - Revista do Desenvolvimento Regional Faccat -, 17(2), 21-35.

Marinho, R. C., \& Ferreira, A. (2019). Políticas públicas de desenvolvimento regional em Minas Gerais: o Plano Estratégico de Desenvolvimento Sustentável do Consórcio da Zona da Mata e Campos das Vertentes. Revista Brasileira de Desenvolvimento Regional, 6(2), 125-146. https://doi.org/10.7867/2317-5443.2018v6n2p125-146

Mendonça, F. F., \& Andrade, S. K. A. V. (2018). Consórcio Público de Saúde como arranjo para relação federativa e o processo de regionalização. Redes (St. Cruz Sul, Online), 23(3), 206-224.

Monteiro, V. L., \& Brito Junior, I. de. (2017). A situação atual de implementação da política nacional de proteção e defesa civil no estado de São Paulo. Revista Percursos, 18 (36), 194-223. https://doi.org/10.5965/1984724618362017194

Nascimento Neto, P. N. N., \& Moreira, T. A. (2012). Consórcio intermunicipal como instrumento de gestão de resíduos sólidos urbanos em regiões metropolitanas: reflexões teórico-conceituais. Revista Brasileira de Gestão e Desenvolvimento Regional, 8(3), 239-282. 


\section{Fortalecendo laços}

Neves, L. A., \& Ribeiro, J. M. (2006). Consórcios de saúde: estudo de caso exitoso. Cadernos de Saúde Pública, 22(10), 22072217. https://doi.org/10.1590/s0102-311x2006001000027

Nogueira, F. R., \& Canil, K. (2017). Cartas geotécnicas de aptidão à urbanização: instrumento de planejamento para prevenção de desastres e para a gestão do uso do solo. In: Anais do XVII Encontro Nacional da Associação Nacional de PósGraduação e Pesquisa em Planejamento Urbano e Regional ENANPUR, 1-15, São Paulo: ENANPUR.

Nogueira, F. R., Canil, K., Sulaiman, S. N., Moura, R. B., Silva, L.R.E. (2021). Caminhos participativos para a gestão de riscos e desastres. Conectadas Revista Interdisciplinar de Extensão e Cultura da Universidade Federal do ABC, 3, 192-193.

Recuperado em 9 de setembro de 2020, de https://conectadas.proec.ufabc.edu.br/wp-content/uploads/2021/03/3edconectadas.pdf

Nogueira, F. R., Oliveira, V. E. de, \& Canil, K. (2014). Políticas públicas regionais para gestão de riscos: o processo de implementação no ABC, SP. Ambiente \& Sociedade, 17(4), 177-194. https://doi.org/10.1590/1809-

4422asoc1100v1742014

Nunes Rodrigues, J. (2011). Cooperação intermunicipal na França e no Brasil em perspectiva comparada. Mercator - Revista de Geografia Da UFC, 10(23), 23-31.

Observatório Municipalista de Consórcios Públicos (2020). Mapa. Recuperado em 15 de setembro de 2020, de http://www.consorcios.cnm.org.br/

Oliveira, J. V. de. (2013). Cooperação Intermunicipal de Interface Multisetorial Direta e Desenvolvimento Metropolitano Sustentável Conceitos e perspectivas de análise em governança metropolitana. Revista Movimentos Sociais e Dinâmicas Espaciais, 2(2), 92-120. https://dialnet.unirioja.es/servlet/articulo?codigo=5842570

Pereira, G. A., \& da Silva Moreira, T. B. (2016). Consórcio Público Intermunicipal: características dos municípios participantes. Revista de Políticas Públicas, 20(1), 307-325.

Ré, E. S., \& Oliveira, V. E. de. (2018). Cooperação intergovernamental na política de mobilidade urbana: o caso do Consórcio Intermunicipal do ABC. Urbe. Revista Brasileira de Gestão Urbana, 10(1), 111-123. https://doi.org/10.1590/21753369.010.001.ao09

Ribeiro, H. M. D., \& Dotto, D. M. R. (2015). O consórcio público para desenvolvimento do Alto Paraopeba (Codap/MG) e os reflexos da gestão pública integrada. Redes, 20(1), 88. https://doi.org/10.17058/redes.v20i1.4076

Ribeiro, M. C. P., \& Razuk, N. P. C. (2014). Consórcio público e gerenciamento de resíduos sólidos: aspectos de eficiência e cooperação. Pensar-Revista de Ciências Jurídicas, 19(1), 151-178. https://doi.org/10.5020/2317-2150.2014.v19n1p151

Rocha, C. V. (2016). A cooperação federativa e a política de saúde: o caso dos Consórcios Intermunicipais de Saúde no estado do Paraná * Introdução A origem do problema: descentralização e cooperação federativa. Caderno Metrópole, 18(36), 377-399.

Rocha, C. V., \& Faria, C. A. P. (2004). Cooperação intermunicipal, reterritorialização da gestão pública e provisão de bens e serviços sociais no Brasil contemporâneo: a experiência dos Consórcios de Saúde de Minas Gerais. Cadernos Metrópole, 11, 73-105.

Saito, S. M., Assis Dias, M. C. de, Ribeiro, D. F., Alvalá, R. C. dos S., Souza, D. B. de, Santana, R. A. S. de M., Souza, P. A. de, Ribeiro, J. V. M., \& Stenner, C. (2020). Disaster risk areas in Brazil: outcomes from an intra-urban scale analysis. International Journal of Disaster Resilience in the Built Environment,). 12 (2), 238-250. https://doi.org/10.1108/IJDRBE-012020-0008

Silva Filho, R. I., \& de Barros Corrêa, A. C. (2017). Consórcio intermunicipal de saneamento básico e implantação da política nacional de resíduos sólidos (PNRS) do Vale do Açú (RN). Revista GeoInterações, 1(1), 33-53.

Silveira, R. C. E. da, \& Philippi, L. S. (2008). Consórcios Públicos: uma alternativa viável para a gestão regionalizada de resíduos sólidos urbanos. Redes. Revista Do Desenvolvimento Regional. 13 (1), 205-224.

https://doi.org/10.17058/redes.v13i1.410

Simão, N. M., Dalmo, F. C., Nebra, S. A., \& Sant'ana, P. H. de M. (2018). A Política Nacional de Resíduos Sólidos e a Estratégia de Formação de Consórcios Públicos Intermunicipais. Revista de Políticas Públicas. 21 (2), 891-913.

https://doi.org/10.18764/2178-2865.v21n2p891-914

Thesing, N. J., Allebrandt, S. L., Nuske, M. A., \& Gessi, N. L. (2018). Organização Intermunicipal: estudo de caso do Consórcio Público de Saúde na Região Fronteira Noroeste do Rio Grande do Sul. Redes (St. Cruz Sul, Online), 23(3), $188-205$.

https://doi.org/10.17058/redes.v23i3.12155 
United Nations Disaster Risk Reduction - UNDRR. (2017). Terminology - UNDRR. Recuperado em 8 de setembro de 2020, de https://www.undrr.org/terminology

United Nations International Strategy for Disaster Reduction - UNISDR. (2015). Sendai Framework for Disaster Risk Reduction 2015-2030. Recuperado em 8 de setembro de 2020, de https://www.undrr.org/publication/sendai-frameworkdisaster-risk-reduction-2015-2030

Ventura, K. S., \& Suquisaqui, A. B. V. (2020). Aplicação de ferramentas SWOT e 5W2H para análise de consórcios intermunicipais de resíduos sólidos urbanos. Ambiente Construído, 20(1), 333-349. https://doi.org/10.1590/s167886212020000100378

Wilches-Chaux. G. (1993). La vulnerabilidad global. In: Los desastres no son naturales. Recuperado em 8 de setembro de 2020, de https://www.desenredando.org/public/libros/1993/ldnsn/html/cap2.htm

Xavier, T. R., Wittmann, M. L., Inácio, R. de 0., \& Kern, J. (2013). Desenvolvimento regional: uma análise sobre a estrutura de um consórcio intermunicipal. Revista de Administração Pública, 47(4), 1041-1066. https://doi.org/10.1590/S003476122013000400011

Editor responsável: Rodrigo Firmino

Recebido: 25 nov. 2020

Aprovado: 30 ago. 2021 